\title{
An Association between a Functional Polymorphism in the Monoamine Oxidase A Gene Promoter, Impulsive Traits and Early Abuse Experiences
}

\author{
Yung-yu Huang', Sarah P Cate', Cristina Battistuzzi', Maria A Oquendo', David Brent ${ }^{2}$ and J John Mann*, \\ 'Department of Neuroscience, New York State Psychiatric Institute, Department of Psychiatry, Columbia University College of Physicians \& \\ Surgeons, New York, NY, USA; ${ }^{2}$ Division of Child and Adolescent Psychiatry, Western Psychiatric Institute and Clinic, University of Pittsburgh School \\ of Medicine, Pittsburgh, PA, USA
}

\begin{abstract}
Monoamine oxidase A (MAOA) activity is altered in mood disorders and lower activity associated with aggressive behavior. The gene has a functional polymorphism with a variable number tandem repeat (VNTR) in the upstream regulatory region (MAOA-uVNTR). In this study, we examined possible associations between the MAOA-uVNTR polymorphism and mood disorders, suicidal behavior, aggression/impulsivity, and effects of reported childhood abuse. In total, 663 unrelated subjects with a psychiatric disorder and I04 healthy volunteers were genotyped for the 30 base pair functional VNTR. A novel repeat variation was identified. No statistically significant associations were found between this functional MAOA-uVNTR polymorphism and mood disorders or suicide attempts. However, the lower expression allele was associated with a history of abuse before 15 years of age in male subjects and with higher impulsivity in males but not females. Our results suggest that the lower expression of the MAOA-uVNTR polymorphism is related to a history of early abuse and may sensitize males, but not females, to the effects of early abuse experiences on impulsive traits in adulthood. The polymorphism may be a marker for impulsivity that in turn may contribute to the risk for abuse. This trait could then be further aggravated by abuse.

Neuropsychopharmacology (2004) 29, |498-1505, advance online publication, 19 May 2004; doi: I 0. I038/sj.npp. 1300455
\end{abstract}

Keywords: monoamine oxidase; suicide; mood disorders; aggression; impulsivity; polymorphism

\section{INTRODUCTION}

Monoamine oxidase (MAO), as a catabolic enzyme, regulates monoamine transmitter levels in the central nervous system. The activity of this enzyme is partly genetically regulated. The genes encoding the $\mathrm{A}$ and $\mathrm{B}$ forms of human monoamine oxidase enzymes (MAOA and $\mathrm{MAOB}$ ) are located together on the short arm of $\mathrm{X}$ chromosome, between bands Xp11.23 and Xp11.4. The MAOA gene has several common polymorphisms: (1) a dinucleotide repeat polymorphism (MAOA-CA) near exon 2 (Black et al, 1991); (2) a 23 bp variable number tandem repeats (VNTR) near exon 1 (MAOA-VNTR) (Hinds et al, 1992); (3) two functional restriction fragment length polymorphisms (Fnu4HI and EcoRV) (Lim et al, 1994);

\footnotetext{
*Correspondence: Dr JJ Mann, Department of Neuroscience, New York State Psychiatric Institute, I05I Riverside Drive, Unit 42, New York, NY I0032, USA, Tel: + I 212543 557I, Fax: + I 2125436017 , E-mail: jjm@columbia.edu

Received 19 November 2003; revised 19 November 2003; accepted 30 January 2004

Online publication: 10 March 2004 at http://www.acnp.org/citations/ Npp03 100403047/default.pdf
}

and (4) a $30 \mathrm{bp}$ functional VNTR polymorphism (MAOAuVNTR) (Sabol et al, 1998). Sabol et al (1998) first reported a functional repeat polymorphism in the promoter region of the MAOA gene, which consists of a 30-bp repeat with 3, $3.5,4$, and 5 copies. Alleles with 3.5 or 4 repeat transcribed 2-10 times more efficiently in human cell lines compared with alleles with 3 or 5 copies of the repeats. Deckert et al (1999) largely replicated these results but reported that, in addition to other longer alleles ( 3.5 and 4 repeats), the allele with 5 repeats was associated with higher transcriptional activity.

The nonpromoter MAOA gene polymorphisms have been implicated in mood disorders, aggression, and suicide. Some studies found that the MAOA CA and VNTR polymorphisms were associated with bipolar affective disorder (Lim et al, 1994; Kawada et al, 1995; Rubinsztein et al, 1996; Preisig et al, 2000). Other studies reported no association of MAOA and bipolar disorder (Craddock et al, 1995; Nothen et al, 1995; Parsian and Todd, 1997; Muramatsu et al, 1997) or unipolar disorder (Kunugi et al, 1999; Syagailo et al, 2001; Serretti et al, 2002). However, contrary to these negative reports, an association with bipolar disorder was found in one meta-analysis (Furlong et al, 1999). No association has been reported with major 
depressive disorder (unipolar depression) (Serretti et al, 2002; Syagailo et al, 2001; Kunugi et al, 1999).

Manuck et al (2000), in a study of the MAOA-uVNTR, observed that males with lower expression variants of this polymorphism scored significantly lower on a composite measure of dispositional aggressiveness and impulsivity and showed more pronounced serotonergic responsivity compared with males with higher expression variants. This result is at variance with several subsequent studies. Individuals who have the MAOA-uVNTR genotype conferring higher expression of MAOA, and who report a history of abuse in childhood (ages 3-11 years), have been found less likely to manifest antisocial psychopathology (Caspi et al, 2002). High MAOA activity somehow reduces vulnerability to the effects of abusive experience in childhood on adult behavior. In addition, the lower expression variants of this polymorphism have been associated with antisocial behavior in male alcohol-dependent patients (Samochowiec et al, 1999).

Animal studies have implicated MAOA in aggressive behavior. Aggression is intensified in the MAOA knockout mouse (Cases et al, 1995) and MAO inhibition during development induced pathological aggression in mice (Mejia et al, 2002). A single-family extended pedigree study in Holland found that a mutation in the MAOA gene that results in a loss of enzyme activity was associated with impulsivity, aggression, and mental retardation in males (Brunner et al, 1993a, b). More recently, the high expressing alleles of this polymorphism were reported to be associated with greater impulsivity and attention deficit hyperactivity disorder (ADHD) (Manor et al, 2002).

There is no agreement about the relationship between MAO activity and suicidal behavior. Low platelet MAOB levels and suicidal behavior has been reported in several studies (Gottfries et al, 1975; Buchsbaum et al, 1977; Meltzer and Arora, 1986). Sherif et al (1991) found greater MAOA activity, in the hypothalamus of suicide victims with a history of depression, but no differences in activity in frontal cortex or cingulate cortex was observed. Mann and Stanley (1984) found no differences in MAOA or MAOB enzyme kinetics in the prefrontal cortex of violent suicide victims. The MAOA-uVNTR polymorphism has been associated with suicide attempts in bipolar patients, particularly in female bipolar patients (Ho et al, 2000), and with suicide in depressed males ( $\mathrm{Du}$ et al, 2002). Although other studies report no association of the promoter VNTR with suicidal behavior in mood disorders (Kunugi et al, 1999; Ono et al, 2002).

Many previous studies have been limited by their focus on a limited aspect of psychopathology such as aggression and childhood abuse without considering mood disorders or suicidal behavior. Therefore, in this study, we examined possible associations between the functional MAOA-uVNTR polymorphism and aggressive behavior, suicidal behavior, mood disorder, and a reported history of childhood abuse.

\section{MATERIALS AND METHODS}

\section{Subjects}

This study included 766 subjects. Totally, 663 had a mood disorder psychiatric diagnosis (males: 286; females: 377 ) and were recruited having been referred for evaluation and treatment of a mood disorder. Ethnic breakdown of psychiatric subjects included 456 (68.8\%) Caucasians, 110 (16.6\%) African-Americans, 10 (1.5\%) Asians, 79 (11.9\%) Hispanics, and eight (1.2\%) subjects categorized as 'other'. 103 subjects (56 males, 47 females) were healthy volunteers with no previous history of psychiatric illness or substance abuse on the basis of a SCID I assessment for DSM-IV criteria (1994) and no cluster B category personality disorder based on a SCID II assessment. All subjects were screened medically (history, examination, laboratory tests) to exclude active medical illness and particular neurological disorders or significant past head injury. Ethnic composition was comparable to the psychiatric subject group. Mean age of subjects (37.6 \pm 12.9 years) was comparable to healthy volunteers ( $38.8 \pm 15.3$ years). Subjects were grouped according to the following psychiatric disorders: major depressive disorder or bipolar disorder using the SCID I. Aggressive, impulsive behaviors were rated using the Barratt Impulsiveness Scale (Barratt, 1985, 1994); the Brown-Goodwin Life History of Aggression interview (Brown et al, 1982, 1979); and the BussDurkee Hostility Inventory (Buss and Durkee, 1957). Screening questions at intake interview assessed physical and sexual abuse and age of occurrence. All subjects gave written, informed consent as required by the Institutional Review Board.

\section{Genotyping}

DNA was obtained from blood samples or from squamous epithelium collected from buccal mucosa using cheek swabs (Puregene Kit, Gentra Systems, Minneapolis, MN, USA). DNA was then extracted from lymphocytes using our previously published method (Huang et al, 2003) and from squamous epithelial cells according to the manufacturer's standard recommended procedure. PCR was performed in a volume of 201 containing $100-200 \mathrm{ng} \mathrm{DNA} ; 25 \mathrm{mM} \mathrm{MgCl}$; $1 \%$ of DMSO or BSA; $1 \times$ PCR buffer; $10 \mathrm{mM}$ dATP, dGTP, $\mathrm{dCTP}$, and dTTP; $100 \mathrm{ng} / \mathrm{l}$ of two primers, MAOAPr-3 $\left(5^{\prime}\right.$-TGCTCCAGAAACATGAGCAC- $\left.3^{\prime}\right)$ and MAOAPr-4 (3'TAGACTTGGGGATCCGACTG-5'); and 1 U RedTaq polymerase (Sigma, St Louis, MO, USA). The samples were preheated at $94^{\circ} \mathrm{C}$ for $5 \mathrm{~min}$, denatured at $94^{\circ} \mathrm{C}$ for 35 cycles of $30 \mathrm{~s}$ each, annealed at $55^{\circ} \mathrm{C}$ for $30 \mathrm{~s}$, with extension at $72{ }^{\circ} \mathrm{C}$ for $40 \mathrm{~s}$ in a Stratagene Robocycler 96 PCR system. Products were electrophoresed on a $1.8 \%$ NuSieve ${ }^{\circledR}$ 3:1 agarose gel (BMA, Rockland, ME, USA) and stained with ethidium bromide. They were then visualized under UV light and sizes were determined by comparison with a $100 \mathrm{bp}$ DNA sequencing ladder. We identified six different repeats of the $30 \mathrm{bp}$ VNTR PCR fragments: $2,3,3.5,4,5$, and 6 .

\section{Statistical Analysis}

Data analysis was performed using SPSS for Windows, Version 10.1. (SPSS Inc., Chicago, 1999) and EasyStat (Nee, 2001) for allelic frequencies. For the analysis, genotypes were divided into three groups: alleles with 2 or 3 copies of the VNTR in group ' 33 ', those with 3 and 4 copies in group 
' 34 ', and those with 3.5, 4 repeats under the category of group ' 44 '. The alleles with 5 copies of the VNTR have disputed transcriptional activity (Sabol et al, 1998; Deckert et al, 1999). On this basis, we excluded subjects with 5 or 6 repeats from further statistical analyses.

Genotype and allele frequencies were contrasted in patients and healthy volunteers using a contingency table $\chi^{2}$ test with Yates' correction and Fisher's exact test where indicated. The significance level was $p<0.05$ for two-tailed tests. Data are reported as mean $\pm S D$ unless indicated otherwise. An ANOVA and Mann-Whitney test were used to determine if there were differences in aggression and impulsivity scores across genotypes. A general linear model was used to analyze the effects of genotype, abuse, major depression, and the interaction of childhood abuse with genotype on impulsivity.

\section{RESULTS}

We observed six different alleles: 2, 3, 3.5, 4, 5, and 6 repeats. The six repeat allele of the MAOA-uVNTR has not been previously reported, and we found it in only one sample (Figure 1). The frequencies of the shortest (2 repeats) and longest alleles ( 5 or 6 repeats) were very low.

The frequencies of common alleles $(3$ and $3.5+4)$ in the healthy volunteer group were 0.45 and 0.55 , respectively, compared to 0.47 and 0.53 in psychiatric subjects $\left(\chi^{2}=0.08\right.$, $\mathrm{df}=1, p=0.782)$ (Table 1). The genotype distribution for the female healthy volunteer group was in Hardy-Weinberg equilibrium $\left(\chi^{2}=0.47, \mathrm{df}=1, p=0.493\right)$. No differences were found in allelic frequency between the psychiatric subjects and healthy volunteers of either male or female gender $\left(\chi^{2}=0.16, \quad \mathrm{df}=1, \quad p=0.692 ; \chi^{2}=0.00, \quad \mathrm{df}=1\right.$, $p=0.999$, respectively) (Table 1$)$. No significant associations of the MAOA-uVNTR polymorphism were found in male or female subjects with major depressive disorder $\left(\chi^{2}=1.50, \mathrm{df}=1, p=0.220 ; \chi^{2}=0.20, \mathrm{df}=1, p=0.654\right)$, bipolar disorder $\left(\chi^{2}=0.85, \mathrm{df}=1, p=0.357 ; \chi^{2}=0.02\right.$, $\mathrm{df}=1, p=0.878$, respectively), or a history of suicide attempts $\left(\chi^{2}=0.26, \quad \mathrm{df}=1, \quad p=0.608 ; \chi^{2}=1.82, \quad \mathrm{df}=1\right.$, $p=0.178)$ (Table 2).

The frequencies of the 44 allele group for AfricanAmerican, Hispanics, Caucasians, and Asians/Others were $45,54,56$, and $44 \%$, respectively. The genotype frequencies for males in each racial group were $40,51,55$, and $43 \%$, respectively. No significant difference was found between

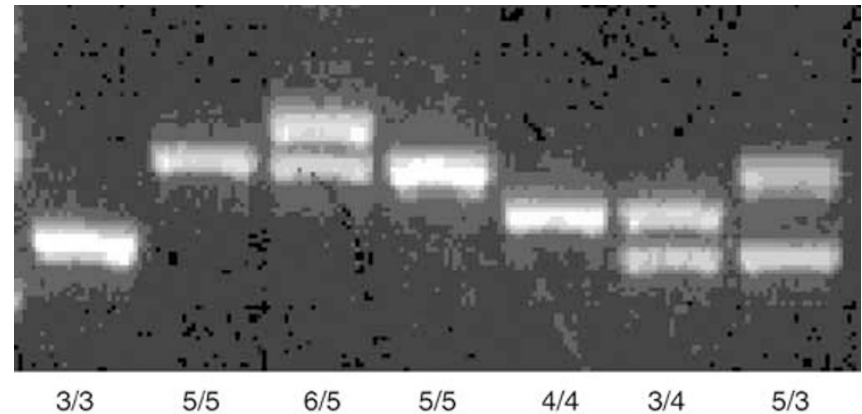

Figure I MAOA VNTR alleles, including a rare six repeat sample, not previously reported.

Table I Genotype Distributions and Allele Frequencies for the Human MAOA-uVNTR Polymorphism in Healthy Volunteers and Psychiatric Subjects with Major Depression, Bipolar Disorders and Suicide Attempt

\begin{tabular}{|c|c|c|c|c|c|c|c|c|c|c|}
\hline & \multirow[b]{2}{*}{$N$} & \multicolumn{3}{|c|}{ Genotype distribution (\%) } & \multirow[b]{2}{*}{$\chi^{2}$} & \multirow[b]{2}{*}{$p$} & \multicolumn{2}{|c|}{ Allele frequency (\%) } & \multirow[b]{2}{*}{$\chi^{2}$} & \multirow[b]{2}{*}{$p$} \\
\hline & & 33 & 34 & 44 & & & 3 & 4 & & \\
\hline Male & 56 & & & & & & $25(45)$ & $31(55)$ & & \\
\hline Female & 47 & II (25) & $21(45)$ & $15(30)$ & & & $43(46)$ & $51(54)$ & & \\
\hline Major depressive episode & 311 & & & & & & $247(46)$ & $287(54)$ & 0.26 & 0.607 \\
\hline Male & 88 & & & & & & $38(43)$ & $50(57)$ & 0.00 & 0.999 \\
\hline Female & 223 & $56(25)$ & $97(44)$ & $70(31)$ & 0.06 & 0.970 & $209(47)$ & $237(53)$ & 0.01 & 0.934 \\
\hline Bipolar disorders & 85 & & & & & & $70(50)$ & $69(50)$ & 0.54 & 0.461 \\
\hline Male & 31 & & & & & & $19(61)$ & $12(39)$ & 1.60 & 0.206 \\
\hline Female & 146 & $38(26)$ & $69(47)$ & $39(27)$ & 0.49 & 0.782 & $145(50)$ & $147(50)$ & 0.29 & 0.588 \\
\hline Patients (all) & 663 & & & & & & 488 (47) & $552(53)$ & 0.08 & 0.782 \\
\hline Male & 286 & & & & & & 139 (49) & $\mid 47$ (5|) & 0.16 & 0.692 \\
\hline Female & 377 & $94(25)$ & |6| (43) & $122(32)$ & 0.08 & 0.961 & $349(46)$ & $405(54)$ & 0.00 & 0.999 \\
\hline
\end{tabular}

Two-tailed tests compared with the allele frequency of healthy volunteer males and those of male patient groups or healthy females and female patient groups. 
Table 2 Genotype Distributions and Allele Frequencies for the Human MAOA-uVNTR Polymorphism in Psychiatric Subjects with or without a History of Major Depression, Bipolar Disorders, Suicide Attempt and Abuse before the Age of 15 Years

\begin{tabular}{|c|c|c|c|c|c|c|c|c|c|c|}
\hline & \multirow[b]{2}{*}{$N$} & \multicolumn{3}{|c|}{ Genotype distribution (\%) } & \multirow[b]{2}{*}{$\chi^{2}$} & \multirow[b]{2}{*}{$p$} & \multicolumn{2}{|c|}{ Allele frequency (\%) } & \multirow[b]{2}{*}{$\chi^{2}$} & \multirow[b]{2}{*}{$p$} \\
\hline & & 33 & 34 & 44 & & & 3 & 4 & & \\
\hline \multicolumn{11}{|c|}{ Major depressive episode } \\
\hline With & 88 & & & & & & $38(43)$ & $50(57)$ & & \\
\hline \multicolumn{11}{|c|}{ Bipolar disorder } \\
\hline With & 31 & & & & & & $18(58)$ & $13(42)$ & & \\
\hline Without & 234 & & & & & & || (47) & $123(53)$ & 0.85 & 0.357 \\
\hline \multicolumn{11}{|c|}{ Suicide attempts } \\
\hline \multicolumn{11}{|c|}{ Abuse before the age of 15 years } \\
\hline With & 43 & & & & & & $26(60)$ & $17(40)$ & & \\
\hline Without & II & & & & & & $2(18)$ & $9(82)$ & 6.27 & 0.012 \\
\hline \multicolumn{11}{|c|}{ Female patients with a history of } \\
\hline \multicolumn{11}{|c|}{ Major depressive episode } \\
\hline With & 223 & $56(25)$ & $97(44)$ & $70(31)$ & & & $209(47)$ & $237(53)$ & & \\
\hline Without & 147 & $36(24)$ & $60(4 I)$ & $51(35)$ & 0.46 & 0.795 & $132(45)$ & $162(55)$ & 0.20 & 0.654 \\
\hline \multicolumn{11}{|c|}{ Bipolar disorder } \\
\hline \multicolumn{11}{|c|}{ Abuse before the age of 15 years } \\
\hline With & 116 & $27(24)$ & $50(44)$ & $37(32)$ & & & $104(46)$ & $122(54)$ & & \\
\hline Without & 46 & II (24) & $19(4 \mid)$ & $16(35)$ & 0.15 & 0.927 & $41(45)$ & $51(55)$ & 0.01 & 0.911 \\
\hline
\end{tabular}

Two-tailed $\chi^{2}$ tests compared with the allele frequency and genotype distribution.

the allelic frequencies and race in males $\left(\chi^{2}=3.89, \mathrm{df}=3\right.$, $p=0.273)$. The genotype distribution between AfricanAmerican and Caucasian or between Hispanic and Caucasian males was not significantly different $\left(\chi^{2}=2.81, \mathrm{df}=1\right.$, $p=0.094 ; \chi^{2}=0.05, \mathrm{df}=1, p=0.822$, respectively) (data not shown).

No significant association of MAOA-uVNTR allelic frequency was observed in male or female subjects with a reported history of abuse $\left(\chi^{2}=0.639, \mathrm{df}=1, p=0.424\right.$; $\chi^{2}=0.033, \mathrm{df}=1, p=0.855$; respectively; see Table 2 ). However, a significant association of the MAOA-uVNTR polymorphism was observed in male subjects with a reported history of childhood abuse before the age of 15 years $\left(\chi^{2}=6.27, \mathrm{df}=1, p=0.012\right)$ (Table 2$)$. The lower expression allele occurred more frequently in males reporting childhood abuse. In contrast, no association was observed in females with a reported history of abuse before the age of 15 years $\left(\chi^{2}=0.15, \mathrm{df}=2, p=0.927\right)$.

No difference was found in lifetime aggression (BrownGoodwin), hostility (Buss Durkee), or impulsivity (Barratt) scores between genotypes in male or female psychiatric subjects (Table 3 ). There was also no difference in the lifetime hostility (BDHI) or aggression (BG) scores and genotype in male or female subjects who reported episodes of abuse before the age of 15 years (Table 4). A general linear model with genotype, childhood abuse history, and major depression as independent variables and impulsivity as dependent variable demonstrated independently signifi- 
Table 3 Lifetime Aggression/Impulsivity and MAOA-uVNTR Genotype in Male and Female Psychiatric Subjects

\begin{tabular}{|c|c|c|c|c|c|c|c|c|c|c|c|}
\hline \multirow[b]{2}{*}{ Aggression scale } & \multirow[b]{2}{*}{ Genotype } & \multicolumn{5}{|c|}{ Males } & \multicolumn{5}{|c|}{ Females } \\
\hline & & $N$ & Mean & SD & $\mathbf{F}$ & $p$ & $\mathbf{N}$ & Mean & SD & $\mathbf{F}$ & $p$ \\
\hline & 34 & & & & & & 148 & 50.30 & 18.53 & & \\
\hline & 44 & 138 & 48.78 & 16.33 & 0.73 & 0.393 & 118 & 53.10 & 18.04 & 1.15 & 0.316 \\
\hline & 34 & & & & & & 155 & 17.63 & 5.49 & & \\
\hline & 44 & 142 & 18.53 & 5.55 & 0.36 & 0.551 & 155 & 13.08 & 5.69 & 0.80 & 0.451 \\
\hline \multirow[t]{2}{*}{ Buss-Durkee Hostility Inventory } & 33 & 132 & 32.89 & 13.09 & & & 87 & 32.79 & 14.19 & & \\
\hline & 34 & & & & & & 149 & 34.05 & 13.49 & & \\
\hline
\end{tabular}

Since MAOA gene is X-linked, here genotype '33' or ' 44 ' refers to one allele for males and two for females. Allele 3 was reported to associate with lower levels of MAOA expression and allele 4 with higher levels. Female heterozygous for the 3 and 4 repeats were denoted as having intermediate levels of MAOA expression. ANOVA analyses were determined between groups by genotype in each aggression or impulsivity scale.

Table 4 Lifetime Aggression/Impulsivity and MAOA-uVNTR Genotype in Male Subjects Reporting Abuse before the Age of I5 Years

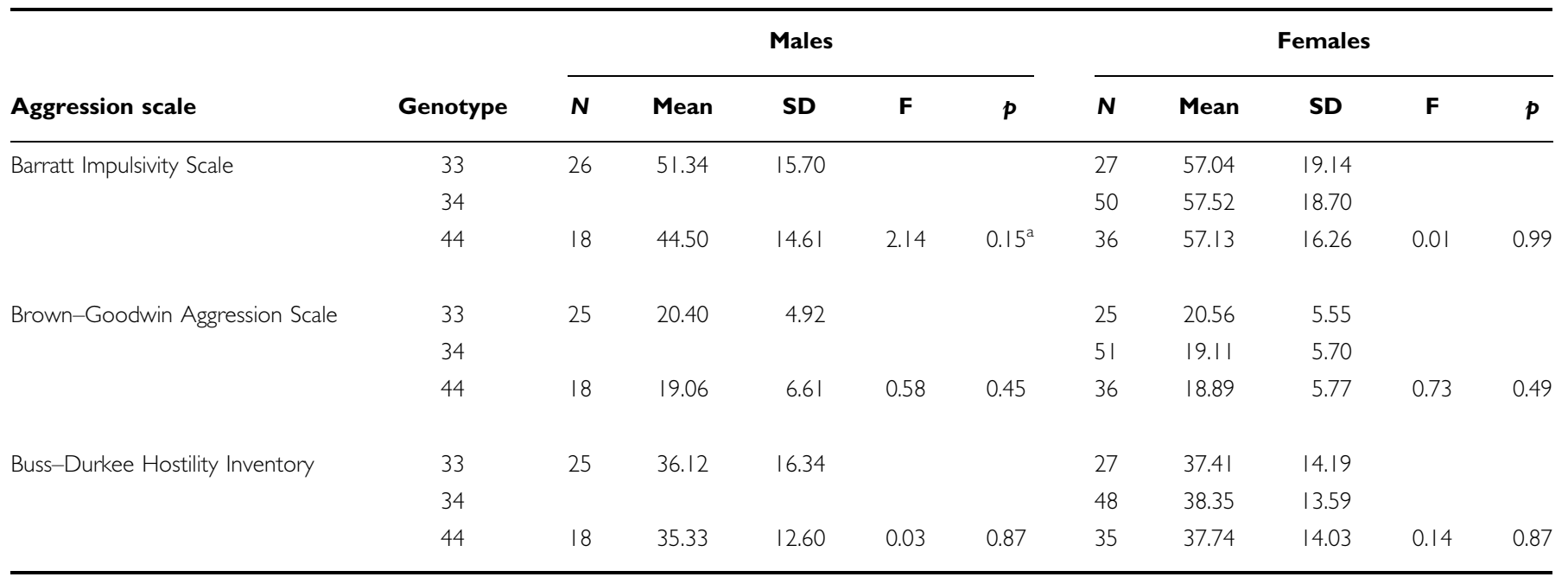

Since MAOA gene is X-linked, here genotype '33' or '44' refers to one allele for males and two for females.

${ }^{a} \mathrm{~A}$ significant gene by abuse history interaction was observed (see text).

cant effects for genotype $(p=0.017)$ and depression $(p=0.017)$, but not abuse $(p=0.336)$. There was significant interaction between genotype and abuse history in males $(p=0.038)$, but not in females $(p=0.851)$. Impulsivity (BIS) was lower in the subgroup of male subjects who reported abuse before the age of 15 years and had the higher MAOA expression genotype (allele 44 group) (44.5 \pm 14.6$)$ compared with male subjects with the lower expression genotype (allele 33 group) $(51.3 \pm 15)$ (Figure 2, Table 4). Impulsivity (BIS) was lower in the higher expression genotype in the Caucasian subgroup $[F(1,24)=4.60, p=$ 0.042]. The assault, irritability, and negativity subscales of the BDHI were subject to an exploratory analysis and no significant differences were observed $[\mathrm{F}(1,42)=$ $0.52, p=0.475 ; \mathrm{F}(1,41)=0.64, p=0.430 ; \mathrm{F}(1,42)=1.04$, $p=0.313$, respectively] (data not shown).
Associations with major depression, bipolar disorder, and suicidal attempts were explored in the early abuse and no early abuse subgroups. A suggestion of an association of suicide attempts with genotype was found in early abuse females $\left(\chi^{2}=6.775, \mathrm{df}=1, p=0.034\right)$ and verified by the Armitage Test $\left(\chi^{2}=6.543, \mathrm{df}=1, p=0.011\right)$. The frequency of the low expressing allele and genotypes was higher in the suicide attempters.

\section{DISCUSSION}

The VNTR polymorphism in the MAOA promoter has been reported to have five alleles containing $2,3,3.5,4$, and 5 copies of a 30-bp tandem repeat. We detected a novel but rare variant with 6 copies of a 30-bp repeat. However, only 


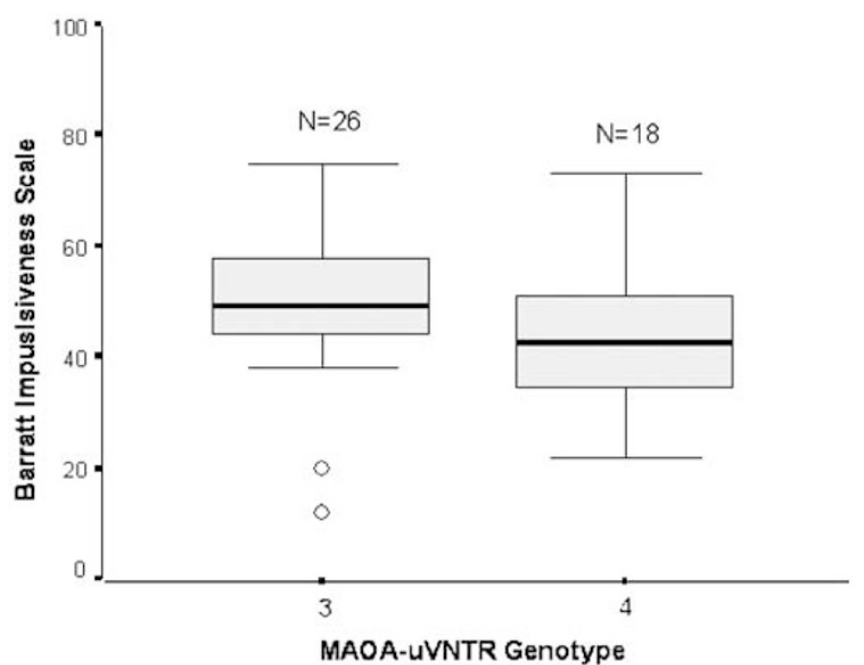

Figure 2 Impusiveness and MAOA-uVNTR genotype in male subjects reporting abuse before the age of 15 years.

the variants with 3 or 4 copies are common in different ethnic populations (Sabol et al, 1998), and this observation was confirmed in our sample. Alleles with 3.5 and 4 copies of the VNTR were first reported to transcribe 2-10 times more efficiently than allele with 3 and 5 repeats (Sabol et al, 1998). However, Deckert et al (1999) found that the allele with 5 copies of the VNTR also resulted in greater luciferase activity. Because of this inconsistency, we excluded subjects with 5 or 6 copies of repeats from further statistical analysis. Our results are similar to the previous published frequencies for healthy controls (Ono et al, 2002; Saito et al, 2002; Samochowiec et al, 1999). Interestingly, the reported frequencies of the long allele $(3.5,4$, or 5 repeats) in male controls in different populations range from a low of $30 \%$ (Preisig et al, 2000) to a high of $73 \%$ (Schulze et al, 2000). Thus, the potential effect of population stratification cannot be ignored.

We found a significant correlation of the high expression MAOA-uVNTR polymorphism with lower impulsivity, but only in adult males who report early childhood abuse. Caspi et al (2002) reported that maltreated males with the same genotype, conferring high levels of MAOA expression, were less likely to display antisocial behavior as adults. Our results suggest that the higher expressing MAOA genotype appears to have a moderating effect on impulsivity that is associated with reported childhood abuse in males but not females. Despite our small sample number of male subjects who reported abuse before the age of $15(N=44)$, number and statistical tests that carry a type I error risk, as well as the exclusion of two outliers, our results support the finding of Caspi et al (2002). Lifetime aggression scores in our sample were not affected by abuse history and genotype. Moreover, we did not score impulsive aggression, which could be expected to relate to impulsivity, a matter for future studies to address.

We also found that childhood abuse was reported more frequently in males, but not females, with lower expressing variant of MAO-uVNTR. Perhaps the familial transmission of impulsive traits in males is associated with less MAOA expression and this trait increases the risk for abuse in childhood. Thus, impulsivity would continue to be expressed in adulthood but not simply as a consequence of abuse but also a risk factor for abuse. This is a different hypothesis to that proposed by Caspi et al (2002), who attributed the protection against the effects of abuse on development of antisocial behavior to more MAOA activity. We extend the Caspi et al (2002) findings in another important direction. That study examined effects of abuse occurring from 3 to 11 years of age, but did not examine the effect of abuse later in childhood. In this study, the protective effect of high MAOA expression in males does not apply to abuse experiences reported to occur after 15 years of age. Thus, if there is a MAOA protective effect with respect to the development and impact of abuse in male, it is only manifest earlier in life when the brain is more vulnerable biobehaviorally to behavioral insults.

The association of the MAOA-uVNTR polymorphism and aggression, as opposed to impulsivity in male subjects, was not found in our present study. Caspi et al (2002) reported on antisocial behavior and other aggression indices such as disposition towards violence and conviction for violence, however, they did not analyze impulsivity separately. The results of both this and the Caspi study contrast with previous reports of an association between the low expression MAOA-uVNTR genotype and less aggression and impulsivity in males (Manuck et al, 2000). The divergence in results may reflect population differences as, for example, Manuck et al (2000) studied a community sample while we studied a psychiatric population.

The effects of MAOA on impulsivity appear to be confined to males in our study. With regard to aggression, Caspi et al (2002) reported detailed results only for males and while noting a trend for a protective effect of high MAOA in females, provide no data. This area warrants further study. In rodent studies, monoamine oxidase inhibitors heightened levels of aggression induced by shock in male Sprague-Dawley rats (Eichelman and Barchas, 1975), and deletion of the MAOA gene caused increased aggression in male mice (Cases et al, 1995). In transgenic mice, Cases et al (1995) noted that MAOA-deficient males with different genetic backgrounds displayed enhanced aggression while pups displayed fearfulness and trembling. Aggressive behaviors in these male MAOA knockout mice, combined with reports from a Dutch pedigree that the males lacking MAOA manifest pathological aggression (Brunner et al, 1993a, b), further support an association of MAOA and aggression in males.

One crucial question is how much this functional MAOAuVNTR polymorphism influences MAOA activity and thereby affects aggressiveness and impulsivity, or mediates or moderates the effect of adverse childhood experiences on adult aggressive and impulsive traits. Alternatively, it may be a marker of impulsive traits that increase the likelihood of exposure to abusive experiences in childhood, which, in turn, further aggravate impulsivity and aggression. Future studies might measure, for example, brain MAOA activity, or level, by methods such as PET scanning and determine its relationship to genotype in vivo. The MAOA gene effect on adult behavior may be due to developmental effects in childhood because of alteration in the monoamine metabolism (Morell, 1993). It is also possible that this functional 
polymorphism is in linkage disequilibrium with another functional polymorphism within the MAOA gene, or other genes that also influence the behavioral variation.

We found that mood disorders and suicidal behavior in male adults do not appear to be related to the allelic variants in the promoter region of the MAOA gene. Separating the sample into those with and without childhood abuse revealed an exploratory finding that females with an early abuse history had an association of the low expressing genotype and allele with suicide attempt behavior as adults. This preliminary finding needs to be replicated and, if confirmed, may indicate that MAOA may influence the previously reported relationship between childhood physical or sexual abuse and suicidal behavior in adulthood (Brodsky et al, 2001). MAOA might influence the risk for suicidal behavior by affecting aggressive/impulsive traits, mood disorders, or other factors. Studies emphasizing a developmental, longitudinal approach and more basic biological and cognitive endophenotypes are promising future directions.

\section{ACKNOWLEDGEMENTS}

This work was partly supported by NIMH Grants (MH62185 and MH48514) and by the Stanley Medical Research Institute.

\section{REFERENCES}

American Psychiatric Association (1994). Diagnostic and Statistical Manual for Mental Disorders, DSM-IV. American Psychiatric Association: Washington, DC.

Barratt ES (1985). Impulsiveness subtraits: arousal and information processing. In: Spence JT, Izard CE (eds). Motivation, Emotion and Personality. Elsevier Science Publisher: Amsterdam. pp 137-146.

Barratt ES (1994). Impulsiveness and aggression. In: Moanthan J, Steadman HJ (eds). Violence and Mental Disorder: Developments in Risk Assessment. University of Chicago Press: Chicago. pp 61-79.

Black GC, Chen ZY, Craig IW, Powell JF (1991). Dinucleotide repeat polymorphism at the MAOA locus. Nucleic Acids Res 19 689.

Brodsky BS, Oquendo MA, Ellis SP, Haas GL, Malone KM, Mann JJ (2001). The relationship of childhood abuse to impulsivity and suicidal behavior in adults with major depression. Am J Psychiatry 158: 1871-1877.

Brown GL, Ebert MH, Goyer PF, Jimerson DC, Klein WJ, Bunney WE et al (1982). Aggression, suicide, and serotonin: relationships to CSF amine metabolites. Am J Psychiatry 139: 741-746.

Brown GL, Goodwin FK, Ballenger JC, Goyer PF, Major LF (1979). Aggression in human correlates with cerebrospinal fluid amine metabolites. Psychiatry Res 1: 131-139.

Brunner HG, Nelen M, Breakefield XO, Ropers HH, van Oost BA (1993a). Abnormal behavior associated with a point mutation in the structural gene for monoamine oxidase A. Science 262: $578-580$.

Brunner HG, Nelen MR, van Zandvoort P, Abeling NG, van Gennip $\mathrm{AH}$, Wolters EC et al (1993b). X-linked borderline mental retardation with prominent behavioral disturbance: phenotype, genetic localization, and evidence for disturbed monoamine metabolism. Am J Hum Genet 52: 1032-1039.

Buchsbaum MS, Haier RJ, Murphy DL (1977). Suicide attempts, platelet monoamine oxidase and the average evoked response. Acta Psychiatr Scand 56: 69-79.
Buss AH, Durkee A (1957). An inventory for assessing different kinds of hostility. J Consult Psychol 21: 343-349.

Cases O, Seif I, Grimsby J, Gaspar P, Chen K, Pournin S et al (1995). Aggressive behavior and altered amounts of brain serotonin and norepinephrine in mice lacking MAOA. Science 268: $1763-1766$

Caspi A, McClay J, Moffitt TE, Mill J, Martin J, Craig IW et al (2002). Role of genotype in the cycle of violence in maltreated children. Science 297: 851-854.

Craddock N, Daniels J, Roberts E, Rees M, McGuffin P, Owen M) (1995). No evidence for allelic association between bipolar disorder and monoamine oxidase A gene polymorphisms. Am J Med Genet 60: 322-324.

Deckert J, Catalano M, Syagailo YV, Bosi M, Okladnova O, Di Bella $\mathrm{D}$ et al (1999). Excess of high activity monoamine oxidase A gene promoter alleles in female patients with panic disorder. Hum Mol Genet 8: 621-624.

Du L, Faludi G, Palkovits M, Sotonyi P, Bakish D, Hrdina PD (2002). High activity-related allele of MAO-A gene associated with depressed suicide in males. NeuroReport 13: 1195-1198.

Eichelman B, Barchas J (1975). Facilitated shock-induced aggression following antidepressive medication in the rat. Pharmaco Biochem Behav 3: 601-604.

Furlong RA, Ho L, Rubinsztein JS, Walsh C, Paykel ES, Rubinsztein DC (1999). Analysis of the monoamine oxidase A (MAOA) gene in bipolar affective disorder by association studies, metaanalyses, and sequencing of the promoter. Am J Med Genet 88: 398-406.

Gottfries CG, Oreland L, Wiberg A, Winblad B (1975). Lowered monoamine oxidase activity in brains from alcoholic suicides. J Neurochem 25: 667-673.

Hinds HL, Hendriks RW, Craig IW, Chen ZY (1992). Characterization of a highly polymorphic region near the first exon of the human MAOA gene containing a GT dinucleotide and a novel VNTR motif. Genomics 13: 896-897.

Ho LW, Furlong RA, Rubinsztein JS, Walsh C, Paykel ES, Rubinsztein DC (2000). Genetic associations with clinical characteristics in bipolar affective disorder and recurrent unipolar depressive disorder. Am J Med Genet 96: 36-42.

Huang YY, Oquendo MA, Harkavy-Friedman JM, Greenhill LL, Brodsky B, Malone KM et al (2003). Substance abuse disorder and major depression are associated with the human 5-HT1B receptor gene (HTR1B) G861C polymorphism. Neuropsychopharmacology 28: 163-169.

Kawada Y, Hattori M, Dai XY, Nanko S (1995). Possible association between monoamine oxidase $A$ gene and bipolar affective disorder. Am J Hum Genet 56: 335-336.

Kunugi H, Ishida S, Kato T, Tatsumi M, Sakai T, Hattori M et al (1999). A functional polymorphism in the promoter region of monoamine oxidase-A gene and mood disorders. Mol Psychiatry 4: 393-395.

Lim LC, Powell JF, Murray R, Gill M (1994). Monoamine oxidase A gene and bipolar affective disorder. Am J Hum Genet 54: $1122-1124$

Mann JJ, Stanley M (1984). Postmortem monoamine oxidase enzyme kinetics in the frontal cortex of suicide victims and controls. Acta Psychiatr Scand 69: 135-139.

Manor I, Tyano S, Mel E, Eisenberg J, Bachner-Melman R, Kotler $M$ et al (2002). Family-based and association studies of monoamine oxidase $\mathrm{A}$ and attention deficit hyperactivity disorder (ADHD): preferential transmission of the long promoter-region repeat and its association with impaired performance on a continuous performance test (TOVA). Mol Psychiatry 7: 626-632.

Manuck SB, Flory JD, Ferrell RE, Mann JJ, Muldoon MF (2000). A regulatory polymorphism of the monoamine oxidase-A gene may be associated with variability in aggression, impulsivity and 
central nervous system serotonergic responsivity. Psychiatry Res 95: 9-23.

Mejia JM, Ervin FR, Baker GB, Palmour RM (2002). Monoamine oxidase inhibition during brain development induces pathological aggressive behavior in mice. Biol Psychiatry 52: 811-821.

Meltzer HY, Arora RC (1986). Platelets markers of suicidality. Ann NY Acad Sci 487: 271-280.

Morell V (1993). Evidence found for a possible 'aggression gene'. Science 260: 1722-1723.

Muramatsu T, Matsushita S, Kanba S, Higuchi S, Manki H, Suzuki $\mathrm{E}$ et al (1997). Monoamine oxidase genes polymorphisms and mood disorder. Am J Med Genet 74: 494-496.

Nee J (2001). EasyStat software. [4.11]. Unit 123, 1051 Riverside Drive, NY, NY 10032, Dept of Res Assessment \& Training, NYSPI.

Nothen MM, Eggermann K, Albus M, Borrmann M, Rietschel M, Korner J et al (1995). Association analysis of the monoamine oxidase A gene in bipolar affective disorder by using familybased internal controls. Am J Hum Genet 57: 975-978.

Ono H, Shirakawa O, Nishiguchi N, Nishimura A, Nushida H, Ueno $\mathrm{Y}$ et al (2002). No evidence of an association between a functional monoamine oxidase a gene polymorphism and completed suicides. Am J Med Genet 114: 340-342.

Parsian A, Todd RD (1997). Genetic association between monoamine oxidase and manic-depressive illness: comparison of relative risk and haplotype relative risk. Am J Med Genet 74: 475-479.

Preisig M, Bellivier F, Fenton BT, Baud P, Berney A, Courtet P et al (2000). Association between bipolar disorder and monoamine oxidase A gene polymorphisms: results of a multicenter study. Am J Psychiatry 157: 948-955.
Rubinsztein DC, Leggo J, Goodburn S, Walsh C, Jain S (1996). Genetic association between monoamine oxidase A microsatellite and RFLP alleles and bipolar affective disorder: analysis and meta-analysis. Hum Mol Genet 5: 779-782.

Sabol SZ, Hu S, Hamer D (1998). A functional polymorphism in the monoamine oxidase A gene promoter. Hum Genet 103: 273-279.

Saito T, Lachman HM, Diaz L, Hallikainen T, Kauhanen J, Salonen JT et al (2002). Analysis of monoamine oxidase A (MAOA) promoter polymorphism in Finnish male alcoholics. Psychiatry Res 109: 113-119.

Samochowiec J, Lesch KP, Rottmann M, Smolka M, Syagailo YV, Okladnova O et al (1999). Association of a regulatory polymorphism in the promoter region of the monoamine oxidase A gene with antisocial alcoholism. Psychiatry Res 86: 67-72.

Schulze TG, Muller DJ, Krauss H, Scherk H, Ohlraun S, Syagailo YV et al (2000). Association between a functional polymorphism in the monoamine oxidase A gene promoter and major depressive disorder. Am J Med Genet 96: 801-803.

Serretti A, Cristina S, Lilli R, Cusin C, Lattuada E, Lorenzi C et al (2002). Family-based association study of 5-HTTLPR, TPH, MAO-A, and DRD4 polymorphisms in mood disorders. Am J Med Genet 114: 361-369.

Sherif F, Marcusson J, Oreland L (1991). Brain gamma-aminobutyrate transaminase and monoamine oxidase activities in suicide victims. Eur Arch Psychiatry Clin Neurosci 241: 139-144.

Syagailo YV, Stober G, Grassle M, Reimer E, Knapp M, Jungkunz G et al (2001). Association analysis of the functional monoamine oxidase A gene promoter polymorphism in psychiatric disorders. Am J Med Genet 105: 168-171. 